\title{
Crianças e Adolescentes em Tratamento Oncológico: uma Análise sobre a Visão do Adiamento do Início ou Interrupção da Educação Escolar
}

doi: https://doi.org/10.32635/2176-9745.RBC.2018v64n3.27

Children and Adolescents in Cancer Treatment: an Analysis of the Vision of Postponing the Beginning or Interruption of School Education

Niños y Adolescentes en Tratamiento Oncológico: un Análisis sobre la Visión del Aplazamiento del Inicio 0 Interrupción de la Educación Escolar

Marcos Vinicius de Carvalho Mendes'; Ângela Cristina Fagundes Góes²; Fernanda Roberta Menezes Brain ${ }^{3}$

Resumo

Introduçáo: A longa durabilidade do processo terapêutico oncológico leva a mudanças na rotina da criança e do adolescente com perda social relevante, impossibilitando-os de frequentar a escola formal durante o período terapêutico. Objetivo: Analisar, na visão de crianças e adolescentes em tratamento oncológico em um hospital especializado da cidade de Salvador - BA, as implicaçóes e elementos envolvidos no adiamento do início da educação escolar ou na sua interrupção. Método: Estudo descritivo com abordagem qualitativa realizada na Oncopediatria do Hospital Aristides Maltez, por meio de entrevistas realizadas individualmente com crianças e adolescentes em tratamento oncológico. Resultados: Foram entrevistadas crianças e adolescentes, sete do sexo masculino e cinco do feminino, com idades entre 8 e 17 anos. Desses, dois nunca estudaram, enquanto os demais puderam frequentar a escola formal. Conclusáo: $\mathrm{O}$ recebimento do diagnóstico repercute de maneiras distintas entre as crianças e adolescentes. Foram verbalizadas dificuldades de ordens clínica e psicológica, tais como efeitos colaterais do tratamento clínico, mudança de rotina e impossibilidade de frequentar a escola formal. Para os adolescentes, lidar com a necessidade do abandono escolar é difícil, uma vez que estão mais próximos de avançar para o ensino superior ou mercado de trabalho. Palavras-chave: Criança; Adolescente; Oncologia; Inclusão Educacional; Enfermagem Pediátrica.

\begin{abstract}
Introduction: The long duration of the oncological therapeutic process leads to relevant changes in the routine of the child and adolescent with social loss, making it impossible to attend formal school during the therapeutic period. Objective: To analyze, in the vision of children and adolescents in cancer treatment in a specialized hospital in the city of Salvador - BA, the implications and elements involved in the postponement of the beginning of school education or its interruption. Method: A descriptive study with a qualitative approach performed at Oncopediatria of the Aristides Maltez Hospital through interviews conducted individually with children and adolescents on cancer treatment. Results: Children and adolescents were interviewed, seven males and five females, aged between eight and seventeen. Out of these, two never studied while the others were able to attend formal school. Conclusion: Receiving the diagnosis has different repercussions among children and adolescents. Difficulties of clinical and psychological orders were verbalized, such as side effects of clinical treatment, change of routine and impossibility of attending formal school, etc. For teenagers, dealing with the need for school drop-out is difficult as they are closer to moving towards higher education or the job market.

Key words: Child; Adolescent; Medical Oncology; Mainstreaming (Education); Pediatric Nursing.
\end{abstract}

Resumen

Introducción: La larga durabilidad del proceso terapéutico oncológico lleva a cambios en la rutina del niño y del adolescente con pérdida social relevantes, imposibilitándole de frecuentar la escuela formal durante el período terapéutico. Objetivo: analizar, en la visión de nińos y adolescentes en tratamiento oncológico en un hospital especializado de la ciudad de Salvador - BA, las implicaciones y elementos involucrados en el aplazamiento del inicio de la educación escolar o interrupción de ésta. Método: Estudio descriptivo con abordaje cualitativo realizado en la Oncopediatría del Hospital Aristides Maltez a través de entrevistas realizadas individualmente con niños y adolescentes en tratamiento oncológico. Resultados: Se entrevistaron nińos y adolescentes, siete del sexo masculino y cinco del femenino, con edades entre ocho y diecisiete años. De ellos, dos nunca estudiaron mientras que los demás pudieron asistir a la escuela formal. Conclusión: La recepción del diagnóstico repercute de maneras distintas entre los nińos y adolescentes. Se han verbalizado dificultades de orden clínico y psicológico, tales como efectos colaterales del tratamiento clínico, cambio de rutina e imposibilidad de asistir a la escuela formal, etc. Para los adolescentes, tratar con la necesidad del abandono escolar es difícil, ya que están más cerca de avanzar hacia la enseńanza superior o el mercado de trabajo.

Palabras clave: Nin̄o; Adolescente; Oncología Médica; Propensíon (Educación); Enfermería Pediátrica.

\footnotetext{
${ }^{1}$ Universidade Federal de Pernambuco. Recife (PE), Brasil. Orcid iD: https://orcid.org/0000-0003-2841-9869

2 Universidade do Estado da Bahia. Salvador (BA), Brasil. Orcid iD: https://orcid.org/0000-0002-0667-0545

${ }^{3}$ Liga Baiana contra o Câncer. Hospital Aristides Maltez. Salvador (BA), Brasil. Orcid iD: https://orcid.org/0000-0002-3354-2485

Endereço para correspondência: Marcos Vinicius de Carvalho Mendes. Rua Mata Pasto, 86 - Areia Branca. Petrolina (PE), Brasil. CEP 56330-040.

E-mail: marcosvcmendes@gmail.com.
} 


\section{INTRODUÇÃO}

O câncer é caracterizado pelo crescimento progressivo, rápido e incontrolável das células. Constitui-se atualmente como problema de saúde pública com estimativa de 600 mil novos casos/ano no Brasil. O acometimento dessa patologia em crianças e adolescentes consiste em $1 \%$ a $3 \%$ dos casos em relação às demais neoplasias malignas, demonstrando ser uma doença rara, com maior probabilidade de cura dependendo da descoberta precoce, da localizaçáo do tumor e sua agressividade ${ }^{1,2}$.

O tratamento radioquimioterápico é agressivo podendo desencadear alopecia, lesóes, ganho ou perda exacerbada de peso, bem como risco de aparecimento de um segundo câncer e mielossupressáo, deixando o indivíduo mais susceptível a adquirir infecçóes e doenças oportunistas, em especial aquele que passa maior tempo em ambientes aglomerados como creches e escolas ${ }^{3,4}$.

A longa durabilidade do processo terapêutico leva a mudanças na rotina da criança e do adolescente, com perda social que inclui a dificuldade ou impossibilidade de frequentar a escola durante o período terapêutico, seja por ordem médica ou por proteção dos seus responsáveis, os quais, fragilizados, dão maior atenção à saúde $\mathrm{e}$ resguardam o processo educativo ${ }^{1,5}$.

Assim, a privação escolar em razão do tratamento oncológico impóe à criança e ao adolescente condiçôes e limitaçóes, tanto relacionadas a fatores biológicos quanto a fatores psicológicos, podendo, ainda, tomar proporçôes que afetam seus responsáveis e aqueles ao seu redor. É reconhecida a perda do convivo social, isolamento, ansiedade e, em casos mais graves, pensamentos relacionados à vida e à sua continuidade.

A Constituição Federal de 1988, em seu artigo 277, afirma que "É dever da família, da sociedade e do Estado assegurar à criança, ao adolescente e ao jovem [...] o direito à vida, à saúde, à alimentação, à educação [...]"; a Lei de Diretrizes e Bases da Educação Nacional (LDB), em seu artigo 58, estabelece que "[...] haverá, quando necessário, serviços de apoio especializado, na escola regular para atender às peculiaridades da clientela de educação especial"”; o Estatuto da Criança e do Adolescente (ECA), artigo 53, reforça a ideia do pleno direito à educação de crianças e adolescentes, com ressalva à igualdade de condição para acesso e permanência na escola devendo ser respeitados por seus educadores ${ }^{8}$.

Incluir a criança e o adolescente com câncer no contexto escolar é um desafio, pois existe o despreparo da família e da comunidade e, principalmente, dos profissionais que os receberão, a fim de promover o seu desenvolvimento na educação formal ${ }^{1,9}$.
Dessa forma, o olhar sobre a educação escolar de crianças e adolescentes em processo terapêutico oncológico, bem como as expressóes e sentimentos manifestados a esse respeito, despertou preocupação e interesse de estudo, ao observar essa populaçáo atendida em um hospital de referência para tratamento de câncer, durante as atividades de estágio/trabalho da Residência Multiprofissional em Saúde em Oncologia. Afinal, o direito à educaçáo, compreendendo a aprendizagem e a escolarização, é um fator determinante na saúde da criança e do adolescente, principalmente nas dos que trazem consigo quaisquer necessidades especiais, durante seu processo de formação como sujeito. Nesse cenário, faz-se crucial a implementação das classes hospitalares, as quais consistem em modalidade de ensino decorrente da educação especial com finalidade de inclusão escolar daqueles que, por estarem impossibilitados, não podem frequentar a educação formal.

Este estudo, que surgiu do desejo de saber qual a visão de crianças e adolescentes em tratamento oncológico sobre o processo de escolarização interrompido ou nunca iniciado em decorrência do tratamento, teve como objetivo geral analisar, na visão de crianças e adolescentes em tratamento oncológico em um hospital especializado da cidade de Salvador - BA, as implicaçôes e elementos envolvidos no adiamento do início da educação escolar ou interrupção desta.

\section{MÉTODO}

Trata-se de um estudo descritivo com abordagem qualitativa que proporcionou a compreensão da realidade por meio da interação e perspectiva do participante com vistas a esclarecer as múltiplas dimensões de um fenômeno complexo ${ }^{10,11}$.

Essa pesquisa foi realizada entre os meses de dezembro de 2017 e fevereiro de 2018, na Oncopediatria do Hospital Aristides Maltez (HAM), Salvador - BA, cuja mantenedora é a Liga Baiana da Luta Contra o Câncer (LBCC). A unidade também mantém convênio formal com a Secretaria de Educação e Cultura (Secult) da Prefeitura Municipal de Salvador por intermédio das Classes Hospitalares para as crianças em tratamento ambulatorial ou em internamento.

A classificação dos participantes como crianças e adolescentes segue o estabelecido pelo ECA, que considera crianças aquelas com idade entre 5 a 12 anos incompletos e adolescentes entre 12 e 18 anos. Destarte, foram critérios de inclusão: ter idades entre 5 a 18 anos incompletos, estar em tratamento oncológico e nunca ter frequentado a escola formal ou que a tenha abandonando, estar internado ou em acompanhamento ambulatorial no hospital locus da pesquisa no período da coleta dos dados; ter as funçóes cognitivas preservadas. 
As entrevistas foram realizadas individualmente. $\mathrm{O}$ tempo máximo era de 15 minutos, permitiu-se a presença do responsável, sob a condição de não interferência. Os responsáveis entrevistadores-autores da pesquisa, um do sexo masculino e outra do sexo feminino, possuem titulação de graduação em enfermagem e psicologia, respectivamente. Realizou-se um treinamento de um mês, sendo executadas duas entrevistas-piloto para validação dos roteiros, porém estes não fizeram parte do estudo final.

Foram, conforme citado, utilizados dois roteiros norteadores para a produçáo dos dados, elaborados pelos pesquisadores, possibilitando, assim, a identificação de conteúdos considerados relevantes para o estudo. Os roteiros utilizados eram semiestruturados, sendo a primeira parte, para ambos questionários, relacionada aos dados do pesquisado, como: se eram crianças ou adolescentes, sexo, idade atual e idade na época do diagnóstico, tempo de duraçáo do tratamento, se abandonou ou nunca frequentou a escola, e com quais familiares convive. A segunda parte da entrevista possuía uma pergunta condutora para ambos os grupos, os quais eram instigados a falar sobre suas rotinas após o recebimento do diagnóstico e como eram suas vindas para o hospital. A segunda questão da parte dois era diferenciada, em cada questionário, pois possuía um direcionamento àqueles que nunca frequentaram a escola e àqueles que tiveram que abandoná-la.

Os participantes foram orientados acerca do uso do gravador e, caso houvesse algum que recusasse a utilização do recurso, teria a sua entrevista manuscrita. Nessa perspectiva e com a permissão dos participantes, as entrevistas foram gravadas.

Visando à não identificação dos entrevistados na exposição dos resultados, eles foram organizados como: "C" para crianças e "A" para adolescente, seguidos de um numeral natural. As ordens dos números foram aleatórias, não correspondendo, pois, à ordem das entrevistas.

Os dados obtidos pela transcrição dos depoimentos, sem omissão do material e sem perda do sentido dito, foram analisados a partir da técnica de análise de conteúdo de Bardin ${ }^{12}$. A análise de conteúdo é um conjunto de instrumentos metodológicos sutis em constante aperfeiçoamento que se aplicam aos discursos extremamente diversificados ${ }^{12}$. As etapas operacionais da pesquisa foram cumpridas, sendo elas: pré-análise, exploração do material, tratamento dos resultados obtidos e interpretação. Para esta pesquisa, não foi utilizado nenhum software.
Os conteúdos obtidos foram organizados em três categorias de análise: 1. Significado do processo de adoecimento para as crianças e os adolescentes; 2 . Sentimento experimentado por crianças e adolescentes em decorrência de nunca terem frequentado a escola formal em razão do processo terapêutico; 3 . Abandono da instituição escolar por crianças e adolescentes em virtude do tratamento oncológico.

Todos os participantes aceitaram participar voluntariamente, após a explicação completa e detalhada sobre a natureza da pesquisa, seus objetivos, métodos, benefício previsto e riscos que poderiam ser causados diretamente pelo estudo. Os desconfortos e quaisquer riscos no que diz respeito à reflexão do tema abordado foram minimizados. Além disso, os participantes contaram com o apoio do Serviço de Psicologia do hospital locus da pesquisa.

O estudo está de acordo com a Resolução CNS 466/12 do Conselho Nacional de Saúde, que regulamenta as pesquisas envolvendo seres humanos, sendo aprovado pelo Comitê de Ética em Pesquisa (CEP) da Universidade do Estado da Bahia (Uneb) sob o número de parecer 2.373.271, bem como pelo CEP do HAM, sob o número 2.444.571.

\section{RESULTADOS}

Os dados referentes à caracterização dos participantes desta pesquisa foram organizados em uma tabela para facilitar a visualização dos mesmos (Tabela 1).

Foram entrevistadas crianças e adolescentes, sendo quatro crianças e oito adolescentes internados ou em acompanhamento ambulatorial que abandonaram a escola tradicional ou nunca a frequentaram. Dos 12 participantes, 11 estavam em tratamento quimioterápico, e uma com encaminhamento para uma segunda intervenção cirúrgica. Quanto ao sexo, sete eram do sexo masculino e cinco do feminino. As idades variaram entre oito e 17 anos. Apenas dois entrevistados eram da cidade de Salvador, sendo os demais provenientes de outros municípios baianos.

Dos 12 participantes, apenas duas crianças nunca estudaram, enquanto as demais puderam estudar em uma escola formal.

Nenhuma das crianças e nem os adolescentes pesquisados apresentavam outra doença prévia antes do câncer. Todas as crianças possuíam entre sete meses e cinco anos de tratamento em acompanhamento ambulatorial e tinham a capacidade cognitiva preservada, respondendo a todos os questionamentos dentro de suas limitaçóes. 
Tabela 1. Caracterização das crianças e adolescentes em tratamento oncológico entrevistados

\begin{tabular}{|c|c|c|c|c|c|c|c|}
\hline & & Crianças & $\%$ & Adolescentes & $\%$ & Total & $\%$ \\
\hline & & 4 & $33 \%$ & 8 & $67 \%$ & 12 & $100 \%$ \\
\hline \multirow{2}{*}{ Sexo } & Masculino & 1 & $8 \%$ & 6 & $50 \%$ & 7 & $58 \%$ \\
\hline & Feminino & 3 & $25 \%$ & 2 & $17 \%$ & 5 & $42 \%$ \\
\hline \multirow{2}{*}{ Cidade } & Salvador & 0 & $0 \%$ & 2 & $17 \%$ & 2 & $17 \%$ \\
\hline & Outro município & 4 & $33 \%$ & 6 & $50 \%$ & 10 & $83 \%$ \\
\hline \multirow{3}{*}{ Tratamento } & Quimioterapia & 3 & $25 \%$ & 8 & $67 \%$ & 11 & $92 \%$ \\
\hline & Radioterapia & 0 & $0 \%$ & 0 & $0 \%$ & 0 & $0 \%$ \\
\hline & Cirurgia & 1 & $8 \%$ & 0 & $0 \%$ & 1 & $8 \%$ \\
\hline \multirow{2}{*}{ Doença prévia } & Sim & 0 & $0 \%$ & 0 & $0 \%$ & 0 & $0 \%$ \\
\hline & Não & 4 & $33 \%$ & 8 & $67 \%$ & 12 & $100 \%$ \\
\hline \multirow{4}{*}{$\begin{array}{l}\text { Tempo de } \\
\text { tratamento }\end{array}$} & Entre 7 meses e 1 ano & 0 & $0 \%$ & 2 & $17 \%$ & 2 & $17 \%$ \\
\hline & 1 ano & 2 & $17 \%$ & 3 & $25 \%$ & 5 & $42 \%$ \\
\hline & 2 anos & 0 & $0 \%$ & 2 & $17 \%$ & 2 & $17 \%$ \\
\hline & Entre 3 e 5 anos & 2 & $17 \%$ & 1 & $8 \%$ & 3 & $25 \%$ \\
\hline \multirow{2}{*}{ Escola formal } & Não frequentou & 2 & $17 \%$ & - & - & 2 & $17 \%$ \\
\hline & Frequentou & 2 & $17 \%$ & 8 & $67 \%$ & 10 & $83 \%$ \\
\hline
\end{tabular}

\section{DISCUSSÃO}

\section{O ADOECIMENTO E AS IMPLICAÇÕES E ELEMENTOS ENVOLVIDOS NO ADIAMENTO DO INÍCIO DA EDUCAÇÃO ESCOLAR OU NA SUA INTERRUPÇÃO}

\section{Significado do processo de adoecimento para as crianças e os adolescentes}

As crianças e adolescentes narraram como foi receber a notícia sobre a doença, a mudança do seu dia a dia após a sua descoberta e como eram as vindas ao hospital. O recebimento do diagnóstico de câncer, como o de qualquer outra doença, afeta não somente a vida daqueles que a recebem, mas de suas famílias e das pessoas mais próximas, como os amigos ou a dos que têm estima por elas. É visto, também, que, mesmo em razão da pouca idade, alguns se mostram preocupados com a nova dificuldade imposta $-\mathrm{o}$ enfrentamento da doença. Isso pode ser verificado pelas falas seguintes:

Para mim, foi normal [receber o diagnóstico]. Foi um pouco mais complicada [mudar a rotina]. Tinha que acordar mais cedo que o normal. Eu já estava acostumada com a rotina do colégio que era seis em ponto. Agora eu tinha que acordar mais cedo para poder chegar aqui (A1. 12 anos. Idade do diagnóstico 12 anos).

Eu digo que a vida deu um nó, virou de cabeça pra baixo. No começo, foi um pouco difícil. Antes eu estudava, como eu moro na área rural, ajudava a trabalhar com meus pais e tinha uma rotina bastante esportiva. (A2. 16 anos. Idade do diagnóstico 14 anos).
A minha rotina mudou pouca coisa, mas atingiu mais a rotina dos meus pais. Sempre os vejo conversando e acho desgastante... [pausa]. Às vezes, eu só queria que fosse a última vez a ir ao hospital (A8. 16 anos. Idade do diagnóstico 15 anos).

A perspectiva de mudança por meio do diagnóstico faz com que cada um, a partir de suas experiências já vividas até o presente momento, reaja de uma forma diferente. Alguns demonstram menos preocupação com o agora para o que será para frente. Outros preocupam-se com o que as novas mudanças irão impor aos seus familiares, como o conflito de relaçáo com seus pais, ocasionando, assim, uma desestruturação psicossocial.

Dantas et al. ${ }^{13}$ demonstram que os genitores reorganizam seu cotidiano em função da criança e do adolescente acometidos pela doença, podendo refletir em exaustáo emocional tanto para a criança ou adolescente quanto para os responsáveis. O longo processo de tratamento oncológico pesa sobre os cuidadores, abra-se espaço em especial àqueles que vivem na zona rural que dependem exclusivamente de seus familiares para o cuidar da casa e do trabalho. A condição de saúde altera a dinâmica familiar e, segundo Rubira ${ }^{14}$, o extenso tratamento pesa mais sobre as famílias constituídas por baixa escolaridade e que vivem em situações menos privilegiadas.

Nesse contexto, conviver com uma doença, que agora é parte integrante do seu ser, causa estranheza, uma vez que agora podem acontecer situaçóes que fogem do controle. Ciclos de quimioterapia, efeitos adversos e vontades próprias que, em diversos momentos devem ser suprimidos, fazem parte desse novo ser. Verifica-se nas falas a seguir: 
Eu antes saia para muitos lugares, mudou tudo, né? $\mathrm{O}$ fato de poder cair alguma hora. Não poder sair o tempo todo porque a imunidade está baixa. Não posso comer de tudo como antes, refrigerante principalmente (A6. 17 anos. Idade do diagnóstico 17 anos).

Foi difícil. Mas depois fui me costumando. Eu fazia quimioterapia, tomava remédio, ia para a consulta. Antes eu vinha todo dia, agora eu venho uma vez na semana. Antes era ruim, porque todo dia eu tinha que pegar acesso todo dia, né? (C1. 8 anos. Idade do diagnóstico 7 anos).

As crianças e os adolescentes, então, são forçados a enfrentarem um novo mundo com novas regras, bem como vivenciarem o processo terapêutico recomendado, além de terem que aprender a lidar com suas vontades e desejos não satisfeitos. $\mathrm{O}$ apoio de toda a equipe de saúde multidisciplinar, bem como o da família e sociedade, é essencial nesse momento, pois o enfrentamento dessa nova realidade reflete uma ruptura do processo infantojuvenil. Isso corrobora o estudo de Gomes ${ }^{9}$, que mostra o amadurecimento forçado daqueles que estão passando por um tratamento de saúde longo e traumático, cujo dano não pode ser mensurado, uma vez que envolve fatores psicológicos.

É perceptível que todos compreendam o que está acontecendo e toda a situação. Isso é notório pelo fato da naturalização que as crianças e adolescentes verbalizam. Atribui-se tal fato ao tempo em que eles vivenciam esse processo, conforme transcrito nas falas:

Eu ficava internado. Já fiquei até 10 meses (C3. 8 anos. Idade do diagnóstico 4 anos).

Bom, eu vinha pra cá, mas, depois da cirurgia, eu fiquei dois anos sem vim pra cá. Aí depois eu fui no hospital da minha cidade e ele mandou eu retornar [para o hospital especializado] para fazer uma ressonância. Como eu não estava sentindo dor, ele mandou fazer outra logo[ressonância]. Ai quando eu fiz, que ele [médico] olhou, né? O resultado estava nascendo outro tumor no lugar. Aí vou fazer outra cirurgia, vou internar hoje (C4. 8 anos, Idade do diagnóstico 3 anos).

Agora tá mais tranquilo porque eu só venho uma vez na semana e volto pra casa e fico o resto da semana em casa. Antigamente [no primeiro tratamento] eu ficava aqui meses e agora fico uns três ou cinco dias (A3. Idade:16 anos. Idade do diagnóstico 15 anos).

Outra situação experimentada é a recidiva da doença que implica novos arranjos no seio familiar, estresse emocional, necessidade de mais recursos financeiros e, também, psicológicos, pois significa reviver momentos dolorosos como o retorno ao hospital em longa permanência, o extenso tratamento e manifestaçóes clínicas, desde a queda de cabelo, náuseas e vômitos e até a dor. Compreende-se, pois, que a recidiva pode ser vista como a presença de incerteza quanto à cura. Traz, assim, sentimentos de frustação e sofrimento e, para Arruda-Colli ${ }^{15}$, novas dúvidas que surgem frente à incerteza da nova forma da doença e às novas submissóes ao tratamento. Mazer-Gonçalves, Valle e Santos ${ }^{16}$ enfatizam o óbito da criança e do adolescente como uma vitória do câncer frente à vida, utilizando o termo "batalha" como uma metáfora. Cria-se um cenário mais perverso e inimaginável quando o indivíduo em tratamento é o seu único companheiro.

Dessa forma, para as crianças e adolescentes pesquisados, o processo de adoecimento significa mudanças na rotina individual, bem como de seus núcleos familiares; necessidade de enfrentar a rotina terapêutica considerada desgastante, dolorosa; afastamento ou redução do convívio social.

\section{IMPLICAÇÕES E ELEMENTOS ENVOLVIDOS NO ADIAMENTO DO INÍCIO DA EDUCAÇÃO ESCOLAR OU NA SUA INTERRUPÇÃOO}

\section{Sentimento experimentado por crianças e adolescentes em decorrência de nunca terem frequentado a escola formal em razão do processo terapêutico}

É sabido que a educação é um direito de todos e um dever do Estado e da família, além de ser um dos fatores determinantes e condicionantes à saúde. Contudo, a condição de frequentar a escola formal sofre variaçóes a partir de certas circunstâncias, como o diagnóstico de câncer. Assim, fica no imaginário da criança e adolescente como deve ser a escola.

Dos entrevistados, duas das crianças e adolescentes não puderam frequentar a escola formal por causa da manifestação precoce do câncer. Assim, esses indivíduos, que nunca frequentaram a escola formal, responderam como, em seu pensar, seria a escola formal:

Eu ainda nem estudei. Imagino que era boa. Todo dia eu passava de frente. Aí eu queria estudar. Eu ficava desse jeito, pensando. Mas minha mãe tinha medo (C3. 8 anos. Idade do diagnóstico 4 anos).

Eu tinha muita vontade de estudar. Eu até pedi pra minha mãe me colocar numa escola. Na verdade, ela não me colocou na escola porque ficou com medo do meu problema (C4. 8 anos. Idade do diagnóstico 3 anos). 
A educação especial enquadra-se nas situaçóes que requerem formas alternativas, tais como métodos e técnicas de ensino, recursos educativos, currículos e organização, que favoreçam o acesso e a organização do ensino para os educandos com necessidades educacionais especiais.

Considerando que o tratamento oncológico requer continuidade e demanda tempo para conclusão, surge dificuldade para a ida das crianças e adolescentes à escola formal. As dificuldades vão desde as de ordem material, em razão da distância que contribui para elevar os custos da família, que já enfrenta as demandas financeiras decorrentes do deslocamento para o tratamento do filho, principalmente quando o local de tratamento é em outro município e não no que a família reside, às de origem emocional, sentimental, decorrentes do estado de apreensão e medo que a família tem de expor a criança e o adolescente em processo terapêutico ao ambiente escolar, mesmo quando autorizado pelo médico.

Bianca et al. ${ }^{1}$ e Ferreira ${ }^{5}$ demonstraram, por intermédio de seus estudos, que a fragilidade dos genitores frente ao estado de saúde e doença de seus filhos é calçado em diversos estágios de proteçâo dando maior atenção à saúde, resguardando a criança e o adolescente do processo educativo formal. Contudo, Gomes ${ }^{9}$ demonstra a importância de incluir a criança no contexto escolar, pois ela continua a crescer e a se desenvolver. Isso corrobora o estudo de $\mathrm{Silva}^{17}$, que entrevistou crianças em situaçōes de hospitalização que relataram privação e limitaçôes como brincar, frequentar a escola e conviver em sociedade. Existe a necessidade, então, de as crianças e adolescentes estarem estudando e participando de um convívio comunitário educacional.

Para esses, o atendimento educacional deverá ser realizado em classes, escolas ou serviços especializados, quando as condiçóes específicas dos educandos impedirem a sua integraçáo nas classes comuns de ensino regular. Assim, algumas instituiçóes hospitalares que tratam crianças e adolescentes com câncer oportunizam a chamada Classe Escolar com vista a minimizar as perdas na formação desse grupo populacional.

Quando as limitaçôes do serviço não se mostram atentas às Classes Hospitalares, nesse cenário, os responsáveis assumem o papel de educadores, sendo a mãe a maior responsável por assumir essa função, o que foi evidenciado, quando questionados se, em casa, os ajudavam a ler ou a escrever:

Minha mãe ajudou a ler e a escrever (C3. 8 anos. Idade do diagnóstico 4 anos).

Ajudava. Minha mãe me ensinou a escrever meu nome. Foi ela que me ensinou (C4. 8 anos. Idade do diagnóstico 3 anos).
Para o ECA, é dever da família, da comunidade, da sociedade e do poder público assegurar o respeito à vida, saúde, esporte, lazer, profissionalização, cultura e dignidade, assegurando com absoluta prioridade a educação e a convivência familiar e comunitáriå .

A escola formal é imaginada e desejada pelas crianças e adolescentes que nunca a puderam frequentar, por conta do processo de adoecimento e consequente tratamento. Entretanto, mediante descrição de seus depoimentos, é possível verificar que aqueles conseguem entender os motivos pelos quais não puderam ir à escola.

\section{Abandono da instituição escolar por crianças e adolescentes em decorrência do tratamento oncológico}

A vulnerabilidade observada, inclusive, na fala dos participantes deste estudo, demonstra que urge a efetivação de medidas eficazes que visem a reduzir, o máximo possível, os impactos que, por exemplo, o câncer acarreta na vida dos sujeitos em destaque. Afinal, o ambiente escolar formal é recheado de desafios, sentimentos, valorização humana, além de ser um espaço onde estão presentes amigos e professores. Entretanto, em determinadas condiçóes de saúde, existe a impossibilidade da permanência da criança e do adolescente de frequentarem a escola formal.

Dez participantes desse estudo tiveram que se desvincular da escola formal para iniciar o processo terapêutico. Desse jeito, eles foram solicitados a expressar seus sentimentos a respeito da saída da instituição formadora, conforme se observa nas falas:

Um pouquinho complicado [sair da escola]. Era um lugar que eu gostava bastante era a escola. Principalmente porque eu só via meus amigos no colégio e também eu já tinha outros cursos, mas eu parei de frequentar. E acabou ficando assim (A1. 12 anos. Idade do diagnóstico 12 anos).

Difícil. Porque eu me apegava muito aos estudos e além disso todos os meus amigos... Hoje eu estou longe, entáo... (A2. 16 anos. Idade do diagnóstico 14 anos).

Foi difícil. Eu gostava de ir. A escola era muito boa, no primeiro dia eu fiz amizade com todo mundo, mas agora eu não tenho contato com ninguém. Só no dia do meu aniversário que eu consegui, mas depois náo (C1. 8 anos. Idade do diagnóstico 7 anos).

As falas circularam em torno da convivência escolar, da falta dos amigos, tornando apenas uma lembrança, pois o afastamento dos companheiros de escola foi um fato real e doloroso. $\mathrm{O}$ ambiente educacional é o cenário do desenvolvimento e de função social do indivíduo. A sua 
saída significa a inserção no ambiente hospitalar, o que, por sua vez, significa a busca para um tratamento, esquecendo, por vezes, a necessidade da ciência educacional para esses sujeitos.

Ferreira $a^{5}$ aponta a atividade escolar como uma ponte para a vida que é bloqueada pela atençáo integral para o tratamento do câncer. Logo existe a necessidade de um acompanhamento pedagógico e psicológico, visto que o afastamento da escola e do convívio com os amigos possui repercussóes negativas que pouco são verbalizadas, como presente no trabalho de Silva ${ }^{18}$, no qual o câncer para a criança e adolescente foi visto como uma dicotomia entre vida e morte. Afinal, a possibilidade de morte por causa do câncer é iminente e circunda a cabeça da criança e do adolescente:

Foi muito difícil. Porque eu já tinha perdido um ano. $\mathrm{E}$ eu queria ter terminado o ano. A pessoa tem planos...[pausa] e nunca vai imaginar que uma doença vai acontecer...[pausa], que uma coisa ruim vai acontecer e pode ser o fim (A6. 17 anos. Idade do diagnóstico 17 anos).

Em qualquer fase do tratamento oncológico, as intercorrências se fazem presentes e demonstram as dificuldades a serem enfrentadas pelas crianças e adolescentes, tais como anorexia, mudança no tratamento, náuseas e vômitos e dor. Gomes ${ }^{9}$ e Lisboa ${ }^{19}$ refletem que reincluir a criança portadora de uma doença oncológica em um ambiente escolar é um desafio, tendo em vista o que a doença pode gerar, em especial conflitos e desencorajamento, inferioridade e não adaptação, como demonstrado a seguir:

Eu tomava quimioterapia e ficava esperando ficar doente. Eu sabia que dava febre, emagrecimento (A5. 12 anos. Idade do diagnóstico 11 anos).

Uma das maiores dificuldades é me sentir inferior sabendo que todos os meus amigos estáo com ritmo diferente na escola. Logo eles vão formar e eu vou ficar para trás. Antes eu pensava que ia terminar, trabalhar [pausa] (A8. 16 anos. Idade do diagnóstico 16 anos).

O tempo de afastamento da escola implica não aprender novos conteúdos e não conviver com os colegas por conta da imposição da condição de saúde. Amâncio e Castro ${ }^{20}$ ressaltam a importância de os docentes estarem presentes por meio de visitas na unidade hospitalar ou no atendimento domiciliar. Isso porque as crianças e os adolescentes irão retornar à escola formal após o término do tratamento e possuem expectativas quanto à sua reinserção no ambiente escolar:
$\mathrm{Na}$ verdade, teve a minha professora [...], que ela trazia as atividades do colégio pra ver se eu passava do ano letivo (A1. 12 anos. Idade do diagnóstico 12 anos).

Como previsto na Lei 1.044 , de 21 de outubro de 1969, o aluno, em condiçóes limitantes de saúde, tem o direito ao atendimento domiciliar ${ }^{21}$. Porém, existem situaçôes críticas e consequentes dificuldades a serem enfrentadas:

No começo eu ficava com vergonha. Porque eu ficava careca, mas o pessoal [amigos] não se importavam... (A7. 12 anos. Idade do diagnóstico 9 anos).

Lisboa $^{19}$ propóe, por meio da arte, trabalhar individualmente com crianças e adolescentes, a fim de se estimular sentimentos e sensaçóes nas práticas lúdicas de aprendizagem, o que poderia favorecer a confiança, eliminar a depressáo e o estresse ao deixar a criança e o adolescente estimularem a imaginação, reintegrando atividades de aprendizagem escolar. Em contrapartida, Santos $^{22}$ salienta o uso de tecnologias, informaçôes e comunicaçôes como ferramentas que devem estar presentes na educação. Para tanto, é necessária a oportunidade das Classes Hospitalares, que trabalham em grupo, devendo estas terem recursos suficientes, inclusive tecnológicos, para auxiliarem as crianças e os adolescentes em suas dificuldades.

\section{CONCLUSÃO}

O recebimento do diagnóstico de câncer repercute de diferentes formas para os responsáveis e para as crianças e adolescentes envolvidos no processo. Logo, elementos envolvidos no adiamento do início da educação escolar ou na sua interrupção compreendem o extenso tratamento, que consideramos o fator de maior impacto, uma vez que há a necessidade de modificação de rotina, gastos financeiros, necessidades de apoio psicológico, além do medo dos pais de exporem os filhos ao ambiente externo (escola), dado o seu estado de vulnerabilidade física, evidenciada na baixa imunidade e alteraçóes clínicas indesejadas, como, por exemplo, a alopecia. Os participantes, apesar de estarem vivenciando a doença, preocupam-se com os pais, em face da modificaçáo da vida destes em razão do seu adoecimento.

$\mathrm{O}$ adiamento do início da educação escolar ou sua interrupçáo implica retardar o processo educacional formal da criança e do adolescente e, no caso do último, a conclusão do ensino médio para início de uma nova fase do processo formativo. Para os adolescentes em especial, falar sobre sua experiência de abandono escolar parece ser mais 
doloroso do que para as crianças, por a adolescência ser uma etapa do ciclo vital na qual ocorrem transformaçóes, construção de identidade, e a convivência em grupo de iguais se faz necessária, bem como a conclusão do ensino médio e, por conseguinte, o ingresso no ensino superior, técnico ou mercado de trabalho. A experiência do adoecimento e a percepção das possibilidades, que foram ofuscadas por conta da doença, do tratamento, dos medos e incertezas, levam à reflexão não só sobre a vida como também sobre a finitude do Ser.

A entrada ou reintegração da criança e do adolescente em tratamento oncológico na comunidade educacional é um processo lento que requer empenho e participação das pessoas envolvidas.

Espera-se que esta pesquisa contribua com a reflexão sobre a temática tanto nas instituiçóes de ensino como também nas instituiçóes de saúde, considerando a relevância do tema que envolve pessoas em fase de crescimento e desenvolvimento, cujo aspecto das subjetividades ainda é pouco estudado nos ambientes hospitalares. Espera-se também que contribua com as reflexôes sobre políticas públicas voltadas para os dois grupos populacionais em análise e estimule novos estudos sobre o tema e participação das pessoas envolvidas.

\section{CONTRIBUIÇÕES}

Todos os autores contribuíram igualmente na pesquisa, discussão, coleta de dados, revisão e redação final.

\section{DECLARAÇÃO DE CONFLITO DE INTERESSES}

Nada a declarar.

\section{FONTES DE FINANCIAMENTO}

Não há.

\section{REFERÊNCIAS}

1. Bianca N, Freitas C, Laís J, Estanislau AM. As percepçôes das crianças e adolescentes com câncer sobre a reinserção escolar. Rev Psicopedag. 2016;33(101):175-183.

2. Instituto Nacional de Câncer José Alencar Gomes da Silva. Estimativa 2018: incidência de câncer no Brasil [internet]. Rio de Janeiro: INCA; 2017. [acesso 2018 Ago 15]. Disponível em: http://www.inca.gov.br/ estimativa/2018/estimativa-2018.pdf

3. Viero V, Colomé BC, Hübner FP, Flores CA, Soares de Lima S, Parnov MB. Enfrentamentos da criança com câncer frente ao afastamento escolar devido internação hospitalar. Rev Enferm da UFSM [Internet] 2014 [acesso 2018 Ago 15];4(2):368-77. Disponível em: http:// cascavel.ufsm.br/revistas/ojs-2.2.2/index.php/reufsm/ article/view/10956

4. Arora RS, Challinor JM, Howard SC, Israels T. Improving care for children with cancer in low- and middle-income countries-A SIOP PODC initiative. Pediatr Blood Cancer [Internet]. 2016 [acesso 2018 Ago 15];63(3):387-91. Available from: http://doi.wiley. com/10.1002/pbc. 25810

5. Ferreira AS, Bichalho BP, Neves LF, Menezes TM, Silva TA, Faier TA, et al. Prevalência de ansiedade e depressão em pacientes oncológicos e identificação de variáveis predisponentes. RBC. 2016;62(4):321-8.

6. Brasil. Constituição da República Federativa do Brasil. Brasília, DF: Senado; 1988.

7. Presidência da República (BR). Lei n ${ }^{\circ} 9.394$, de 20 de dezembro de 1996. Estabelece as diretrizes e bases da educação nacional. Brasília, DF: Senado; 1996.

8. Presidência da República (BR). Lei Federal no 8069, de 13 de julho de 1990. Brasília, DF: Diário Oficial da Uniăo; 1990.

9. Gomes IP, Lima KA, Rodrigues LV, Lima RAG, Collet N. Do diagnóstico à sobrevivência do câncer infantil: perspectiva de crianças. Texto Context - Enferm [Internet]. 2013 [acesso 2018 Out 5];22(3):671-9. Disponível em: http://www. scielo.br/scielo.php?script=sci_arttext\&pid=S010407072013000300013\&lng=pt\&tlng=pt

10. Godoy AS. Pesquisa qualitativa: tipos fundamentais. Rev Adm Empres. 1995;35(3):20-9.

11. Minayo MCS. O desafio do conhecimento: pesquisa qualitativa em saúde. 9. ed. São Paulo: Hucitec; 2007.

12. Bardin, L. Análise de conteúdo. Sáo Paulo: Ediçôes 70; 2011

13. Costa MA, Agra G, Souza Neto VL, Silva BC, Braz LC, Mendonça AE. Desvelando a experiência de máes de crianças com câncer em uma unidade de cuidados paliativos. Rev Enferm do Centro-Oeste Min [Internet]. 2016 [acesso 2018 Out 5];1(6):2052-65. Dsiponível em: http://www.seer.ufsj.edu.br/index.php/recom/ article/view/965

14. Rubira EA, Marcon SR, Belasco AGS, Gaíva MAM, Espinosa MM. Sobrecarga e qualidade de vida de cuidadores de criança e adolescentes com câncer em tratamento quimioterápico. ACTA Paul Enferm. 2012;25(4):567-73.

15. Arruda-Colli MN, Santos MA. Aspectos psicológicos da recidiva em Oncologia Pediátrica: uma revisão integrativai. Arq Bras Psicol. 2015;67(3):75-93.

16. Mazer-Gonçalves SM, Valle ER, Santos MA. Significados da morte de crianças com câncer: vivências de mães de crianças companheiras de tratamento. Estud Psicol [Internet]. 2016 [acesso 2018 Out 5];33(4):613-22. Disponível em: http:// www.scielo.br/scielo.php?script=sci_arttext\&pid=S0103166X2016000400613\&lng=pt\&tlng=pt 
17. Silva PL, Xavier GC, Oliveira VV, Figueredo ML, Prado PF, Aguiar Filho W. Câncer Infantil: vivências de crianças em tratamento oncológico. Enferm em Foco [Internet]. 2017 [acesso 2018 Out 5]7;7(3/4):51. Disponível em: http://revista.cofen.gov.br/index.php/ enfermagem/article/view/916

18. Silva TP, Leite JL, Santos NL, Silva ÍR, Mendonça AC, Santos MJ, et al. Cuidados de enfermagem à criança com câncer: uma revisão integrativa da literatura. Rev Enferm da UFSM [Internet]. 2013 [acesso 2018 Out 5];3(1):68-78. Disponível em: http://cascavel.ufsm.br/ revistas/ojs-2.2.2/index.php/reufsm/article/view/6918.

19. Amaral MM. Políticas públicas de formação continuada de professores para a educação inclusiva no Brasil: o que temos para hoje? Rev Educ Artes e Inclusão [Internet]. 2017 [acesso 2018 Out 5];13(3):120-40. Disponível em: http://www.revistas.udesc.br/index.php/ arteinclusao/article/view/9841

20. Moreira GE, Salla H. O Atendimento pedagógico domiciliar de alunos que náo podem frequentar fisicamente a escola por motivos de saúde: Revisão Sistemática das investigaçóes realizadas entre 2002 e 2015. Rev Educ Espec [Internet]. 2018 [acesso 2018 Out 5];31(60):119. Disponível em: https://periodicos. ufsm.br/educacaoespecial/article/view/26680.

21. Presidência da República (BR). Decreto-lei no 1.044 , de 21 de outubro de 1969. Institui o exercício domiciliar e dá outras providências. Brasília, DF: Diário Oficial da Uniáo; 1969.

22. Santos J, Abdalla D, Gomes A. Brincando e aprendendo: uma proposta lúdica de inclusão social e digital para pacientes de serviços de Oncologia Pediátrica. An do Work Informática na Esc [Internet]. 2016 [acesso 2018 Out 5];22(1):914. Disponível em: http://www.br-ie. org/pub/index.php/wie/article/view/6635 